\title{
Tensiometer as an Irrigation Management Tool and Its Effect on Water Use and Yield of Open Field Grown Cucumber
}

\author{
Rola Jad Allah ${ }^{1}$ and Nasser Jeber Yousef Sholi ${ }^{2}$ \\ 1. Biology and Biotechnology Department, Arab American University, Jenin, P.O. Box 240, Palestine \\ 2. Department of Environment and Sustainable Agriculture, Palestine Technical University-Kadoorie (PTUK), Tulkarm, P.O. Box 07, \\ Palestine
}

\begin{abstract}
Water is scarce in Palestine and water saving is becoming very important issue. Water management is one of the promising solutions to save water. The purpose of this work was to study the effect of two types of irrigation regimes on water consumption, yield and growth parameters of cucumber (Cucumis sativus L.) under open field conditions. Cucumbers were grown on a silty-clay soil in Palestinian local conditions. The irrigation regimes used were farmer based irrigation (FI) and tensiometer based irrigation (TI). The results showed that there were no significant difference in crop yield between FI (3.5 kg/plant) and TI (3.4 $\mathrm{kg}$ /plant). Dry matter was $14.7 \%$ less in TI treatment than that in FI treatment, while water saving was $35.7 \%$ in TI treatment. Thus, proper use of tensiometer could be utilized for a better use and management of water resource. Selection of proper water potential set-points according to the cultivation season is crucial for satisfactory results.
\end{abstract}

Key words: Tensiometer, cucumber, water use efficiency, water saving.

\section{Introduction}

Agriculture is the largest consumer of fresh water worldwide. There is about $70 \%-80 \%$ of the diverted total water in the arid and semiarid regions used in agriculture [1] and water availability in water limited areas worldwide is predicted to rise to $67 \%$ by 2050 [2].

There are many techniques developed to save water so far, among these, drip irrigation is with its ability to provide small and frequent water application to the plant around its root zone. It is being used worldwide and shows potential in increasing yield and in water saving in a wide range of crops [3-5]. To make drip irrigation technology very efficient and to minimize excessive water use, it is preferred to be coupled with scheduling water application, as excessive irrigation reduces yield, while inadequate irrigation causes water

Corresponding author: Rola Jad Allah, assistant professor, research field: applied biology. stress and reduces production. However, introducing new technology and good water management allows efficient use of water [6]. Tensiometer is one of these technologies, which allow more water use efficiency. It is rapid, cheap and easy devices for monitoring the water status of substrate and useful for fertirrigation scheduling [7]. It is often preferred to other type of substrate moisture sensors because of its simplicity, low cost, accuracy, no influence of temperature and soil osmotic potential [8].

In Palestine, water for irrigation is both scarce and costly. Good water management is necessary to make efficient use of these scares resource. Cucumber is widely planted in Palestine in spring cycle mainly for pickles and under greenhouse conditions for fresh consumption, which constitutes $14.4 \%$ of the total area planted with vegetable crops in the Palestine [9]. Root system of cucumber is sparse and $85 \%$ of root length is concentrated in the upper $30 \mathrm{~cm}$ top of soil 
layer. For this, water is an important limiting factor in the production and quality of cucumber [10]. When grown in open field of a semi-arid climate, cucumber is subjected to direct sunlight, high temperature and wind, resulting in high crop evapotranspiration $(E T c)$, therefore, demanding large amount of water. In contrast, shade greenhouses favor plant growth, since plants are less subjected to water stress, direct sunlight is avoided, wind speed reduces and ETC is low.

The purpose of this research was to evaluate the possibility of using the tensiometer as a management tool to supply water for irrigation of cucumber (Cucumis sativus L.) in open filed drip irrigation system to improve water use efficiency and reduce water consumption.

\section{Materials and Methods}

\subsection{Site Description and Experimental Data}

A field study was conducted at the Qabatyah station at National Agriculture Research Center (NARC) located at Qabatayh, Jenin, Palestine. The soil of the experimental site is classified as clay texture. Commercial organic fertilizer at a rate of $200 \mathrm{~kg} / 1,000$ $\mathrm{m}^{2}$ was applied prior to planting and mixed into the soil. A drip irrigation system was designed with emitter discharge at a rate of $4 \mathrm{~L} / \mathrm{h}$ and with spacing between emitters of $30 \mathrm{~cm}$ installed at spacing between laterals of $2 \mathrm{~m}$.

\subsection{Seedlings Cultivation}

Cucumbers (Cucumis sativus L.), Yamama variety, were planted on March, 2016. Each row has 25 plants with $30 \mathrm{~cm}$ apart and with $2 \mathrm{~m}$ space between rows. Both treatments received the same amount of fertilizers. NPK compound fertilizer (13:13:13) at a rate of $13 \mathrm{~kg} / 1,000 \mathrm{~m}^{2}$ was applied at $3 \mathrm{~d}$ intervals through drip irrigation system, during the first growth period which lasted for two weeks starting from transplanting. Also another NPK compound fertilizer $(11: 8: 20)$ at a rate of $430 \mathrm{~kg} / 1,000 \mathrm{~m}^{2}$ was applied during the second and third growth periods for 15 weeks. The amount of compound fertilizers was applied according to the NPK requirement of cucumber crop during the growth periods given as practiced by farmers.

\subsection{Irrigation Treatments}

Two water regimes applied were: farmer irrigation (FI) and tensiometer based irrigation (TI). In FI treatment, the amount of water applied was according to farmer traditionally practicing in his field, which depends mainly on his past experience and on eye observation of plant status as well as growth development stages. In TI treatments, the irrigation depends mainly on the reading of tensiometer, which is kept at depth of $30 \mathrm{~cm}$ where most of the roots present. Irrigation decision was made when the average tensiometer reading reached to $30 \mathrm{kPa}$.

Different amounts of water were applied according to plant development sages and requirements. The amount of applied water in FI treatment was determined according to plant observation and plant growth stages and farmers practice.

The water use efficiency (WUE) was determined according to FAO [11] as Eq. (1):

$$
\text { WUE }=\frac{\text { yield }(\mathrm{kg})}{\text { total water applied }\left(\mathrm{m}^{3}\right)}
$$

\subsection{Plant Measurements}

Total yield and total number of fruit per plant were measured from all plant. Plant height and dry weight of above part were measured from 12 plants per row with total 48 plants. Average total dry matter was determined by whole plants minus fruits. Leaves, roots and stems were separated and weighed to obtain root and shoot (leaves and stem) dry weight, while shoot dry weight was only measured (Table 1) after drying at $70{ }^{\circ} \mathrm{C}$ for $3 \mathrm{~d}$. Harvesting was done manually for a period of two months and then the total cucumber fruits produced were calculated. 

and Yield of Open Field Grown Cucumber

\subsection{Statistical Analysis}

Data were analyzed and examined statistically using analysis of variance (ANOVA) from the statistical analysis system SPSS appropriate for a randomized complete block design. Means were compared by least significant difference (LSD) test at 5\% level of significance.

\section{Results and Discussion}

The effects of irrigation regimes on cucumber yield are shown in Table 1. The average yield of different treatments indicated that there is no significant difference between two treatments $(P \leq 0.05)$. Researcher suggested that tensiometer based methods was found to produce yields and quality in potato equivalent to those without using tensiometer with significant savings in seasonal irrigation totals [12]. These results proven that using correct amount of water gives proper yield; it might due to the decreased water leaching and increased various physiological processes, better plant nutrient uptake and higher rate of photosynthesis, which might be reflected on more number of fruits and higher fruit weight. Water use efficiency in FI treatment was $25 \mathrm{~kg} / \mathrm{m}^{3}$ and at $\mathrm{T} 2$ treatment $37.7 \mathrm{~kg} / \mathrm{m}^{3}$. This reflects that using tensiometer lead to more water saving without affecting food quantity.

The plants attained higher length for FI, as compared to TI Treatments, but not significantly different. This gives an idea that TI treatment provides the adequate amount of water necessary for normal growth. The plants dry matter in FI treatment was higher than TI treatment at the end of harvesting stage (Table 1).

When using scheduled irrigation methods depending on tensiometer reading, large amount of water were saved and found to be $35.7 \%$ less than for TI compared to FI treatment, where $140 \mathrm{~L}$ and $90 \mathrm{~L}$ per plant was consumed in FI and TI treatment, respectively (Table 2). Results of this study indicated that large amount of water was saved under TI treatment and no significant difference in yield between both treatments. Similar results were obtained by Shae et al. [12].

Data on water use efficiency calculated as the ratio of cucumber yield $(\mathrm{kg})$ to total crop water used $\left(\mathrm{m}^{3}\right)$ for both treatments are shown in Table 2. It is indicated that the water use efficiency of cucumber plants investigated under $\mathrm{TI}$ is higher than FI treatments $\left(23.7 \mathrm{~kg} / \mathrm{m}^{3}\right.$ and $25 \mathrm{~kg} / \mathrm{m}^{3}$, respectively).

It is indicated that TI treatment had higher water use efficiency than that under FI. The water use efficiency is variable and depends on different parameters, like soil water content, volume of water supply, humidity and soil water potential [13]. In this study case, the lower water use efficiency was found under FI treatment. This can be attributed to the fact that large amount of irrigation water was applied in improper way.

Table 1 Average yield, plant height and dry matter of cucumber under T1 and F1 treatments.

\begin{tabular}{llll}
\hline Treatment & Yield (kg/plant) & Plant height $(\mathrm{cm})$ & Average dry weight $(\mathrm{g} / 100 \mathrm{~g}$ of FW) \\
\hline F1 & $3.5^{\mathrm{a}}$ & $140^{\mathrm{a}}$ & $6.8^{\mathrm{a}}$ \\
T1 & $3.4^{\mathrm{a}}$ & $130^{\mathrm{a}}$ & $5.8^{\mathrm{ab}}$ \\
\hline
\end{tabular}

FW: fresh weight. Means followed by the same letter are not significantly different at $P \leq 0.05$.

Table 2 Water consumption and water use efficiency (WUE) in different irrigation treatment.

\begin{tabular}{lll}
\hline Treatment & Water consumption (L/plant) & WUE $\left(\mathrm{kg} / \mathrm{m}^{3}\right)$ \\
\hline F1 & $140^{\mathrm{a}}$ & $25.0^{\mathrm{a}}$ \\
T1 & $90^{\mathrm{b}}$ & $37.7^{\mathrm{b}}$ \\
\hline
\end{tabular}

Data followed by the same letter are not significantly different at $P \leq 0.005$. 


\section{Conclusions}

In this study, a simple and efficient application of tensiometer was successfully demonstrated. With experience working with farmers, they need a simple and practical method to save water. It is demonstrated here that WUE increased by application of tensiometer. These results will be followed in future with field demonstration with farmers in their field to convince about the simple and efficiency of this technique. No doubt there are more accurate techniques, but the adoption by farmer is very low.

\section{Acknowledgments}

Deep thanks to Palestine Technical University -Kadoorie (PTUK) for their financial support and National Agriculture Research Center (NARC) for continuous help.

\section{References}

[1] Fereres, E., and Soriano, M. A. 2007. "Deficit Irrigation for Reducing Agricultural Water Use.” J. Exp. Bot. 58 (2): 147-59.

[2] Wallace, J. S. 2000. "Increasing Agricultural Water Use Efficiency to Meet Future Food Production.” Agriculture, Ecosystems and Environment 82: 105-19.

[3] Rahil, M. H., and Antonopoulos, V. Z. 2007. "Simulating Soil Water Flow and Nitrogen Dynamics in a Sunflower Field Irrigated with Reclaimed Wastewater." Agric. Water Manage. 92 (3): 142-50.

[4] Janat, M. 2003. "Effect of Drip Fertigation on Improvement of Potato Yield and Water Use Efficiency." AECS-A/RRE 126: 1-38.
[5] Bhardwaj, S. K. 2001. "Importance of Drip Irrigation in Indian Agriculture.” Kissan World 28: 32-3.

[6] Deng, X. P., Shan, L., Zhang, H. P., and Turner, N. C. 2006. "Improving Agriculture Water Use Efficiency in Arid and Semi-Arid Areas of China." Agric. Water Manage. 80: 23-40.

[7] Hodnett, M. G., Bell, J. P., Ah-Koon, P. D., Soopramanien, G. C., and Batchelor, C. H. 1990. "The Control of Drip Irrigation of Sugarcane Using Index Tensiometers: Some Comparisons with Control by the Water Budget Method." Agric. Water Manage. 17: 189-207.

[8] Thalheimer, M. 2003. "Tensiometer Modification for Diminishing Errors due to the Fluctuating Inner Water Column.” Soil Sci. Soc. Am. J. 67 (3): 737-9.

[9] Palestinian Central Bureau of Statistics (PCBS). 2011. "Selected Agricultural Indicators about the Crop Production in Palestine, 2010/2011." Accessed March, 2017. http://www.pcbs.gov.ps/Portals/_Rainbow/Documents /Main\%20Agri.2010-2011,Crop\%20ProductionE.htm.

[10] Janoudi, A. K., and Widders, I. E. 1993. "Water Deficits and Fruiting Affect Carbon Assimilation and Allocation in Cucumber Plants." Hortic. Sci. 28 (2): 98-100.

[11] Food and Agriculture Organization of the United Nations (FAO). 1982. "Livestock Production: A World Perspective." Animal Production and Health Division and Policy Analysis Division of FAO. Accessed June, 1983. http://www.fao.org/docrep/017/ap662e/ap662e.pdf.

[12] Shae, J. B., Steele, D. D., and Gregor, B. L. 1999. "Irrigation Scheduling Methods for Potatoes in the Northern Great Plains.” Trans. ASAE 42 (2): 351-60.

[13] Douh, B., Mguidiche, A., Bhouri-Khila, S., Mansour, M., Harrabi, R., and Boujlben, A. 2013. "Yield and Water Use Efficiency of Cucumber (Cucumis sativus L.) Conducted under Subsurface Drip Irrigation System in a Mediterranean Climate." J. Environ. Sci. Toxicol. Food Technol. 2 (4): 46-51. 